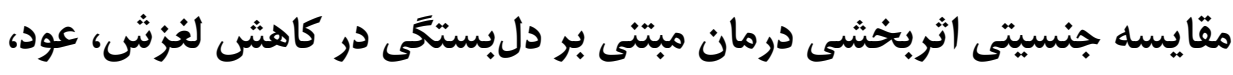

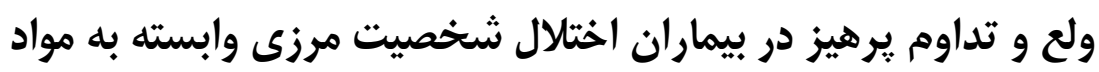

\author{
حجت اله طهماسبيان'، وحيد احمدى"، شهرام مامى' \\ 1) كروه رولنشناسى عمومى، ولحد ايلام، دانشكاه آزاد (سلامى، إيلام، إيرانغ
}

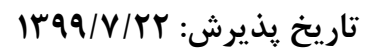

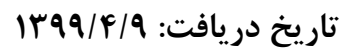

\begin{abstract}
مقدمه: هدف از انجام اين بُووهش، مقايسه جنسيتى اثربخشى درمان مبتنى بر دلبستكى در كاهش لغزش، عود، ولع و تداوم يرهيز در بيماران اختلال شخصيت مرزى وابسته به مواد بوده است.

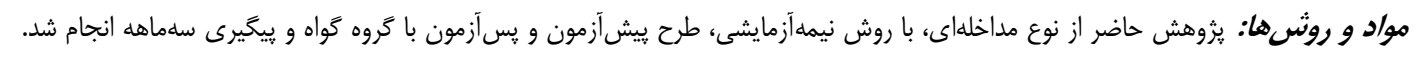

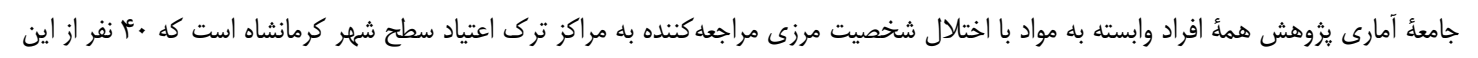

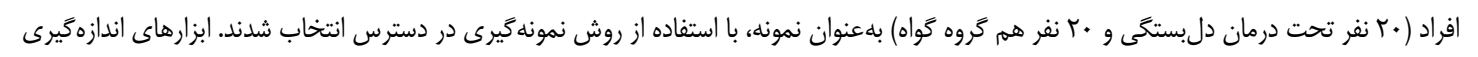

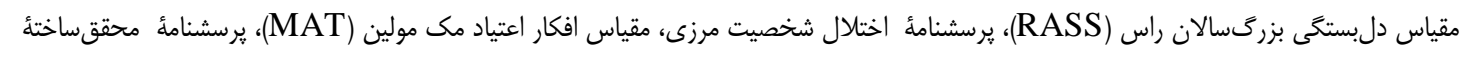

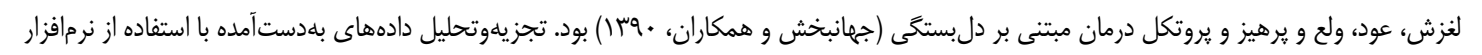

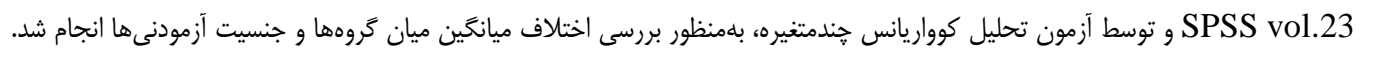

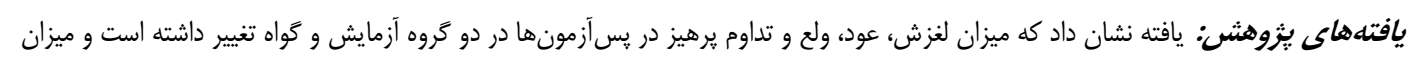

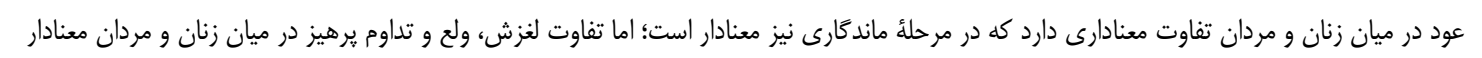

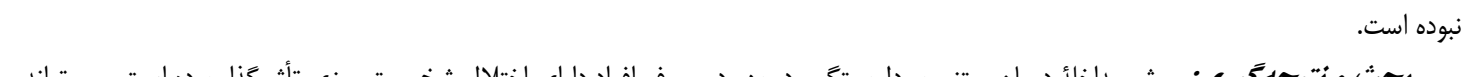

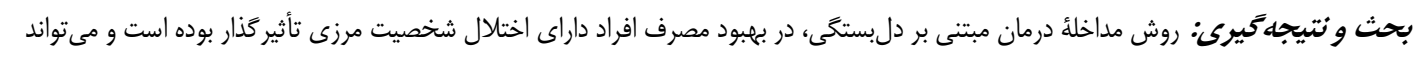
بر كاهش لغزش، عود، ولع و افزايش تداوم يرهيز تأثير داشته باشد.
\end{abstract}

وازههاى كليدى: درمان دلبستخى، لغزش و عود و ولع و تداوم يرهيز، اختلال شخصيت مرزى، زنان و مردان وابسته به

Email:Vahid_ahmadi20@yahoo.com

* نويسندة مسئول: كروه روانشناسى، واحد ايلام ، دانشكاه آزاد اسلامى، ايلام، ايران

Copyright $\odot 2019$ Journal of Ilam University of Medical Science. This is an open-access article distributed under the terms of the Creative Commons Attribution international 4.0 International License (https://creativecommons.org/licenses/by-nc/4.0/) which permits copy and redistribute the material, in any medium or format, provided the original work is properly cited. 
افراد معتاد، با كَذشت مدت نه קֶندان طولانى، بيشتر اين

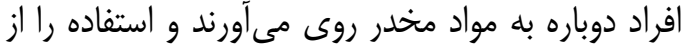
سر خواهند كرفت، موضوع عود مكرر قابل تأمل است (َّ).

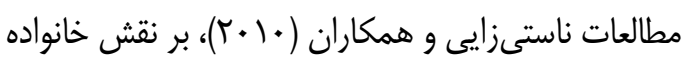

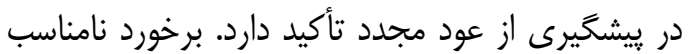
خانواده با فرد معتاد، ارتباط مستقيمى با مسئلة عود خواهد دادي داشت (أ). براساس مطالعة شاطريان و هماداران

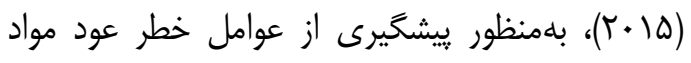
مخدر، به برنامهاى جندبعدى نياز است كه با اجراى آن آن

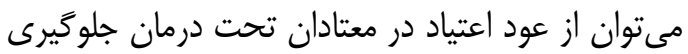

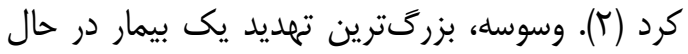

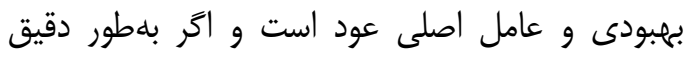

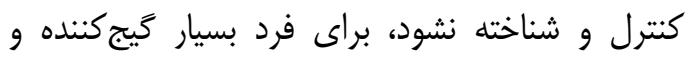

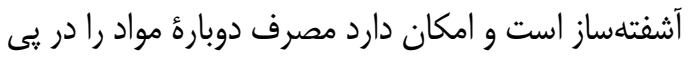

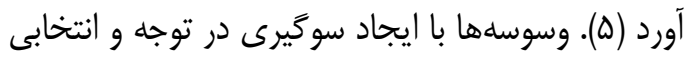

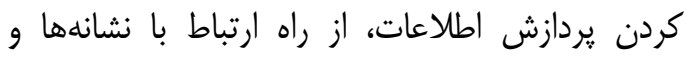
يردازش نسبتاً جذابانهتر اطلاعات مرتبط بات آناه آنها،

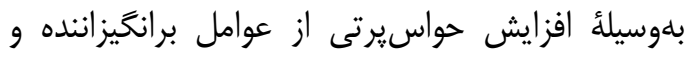
كاهش توانايى تمركز كردن بر آنها و تقويت آكَاهى از عاز

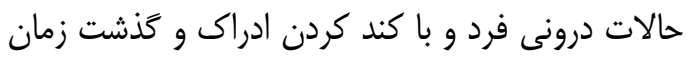

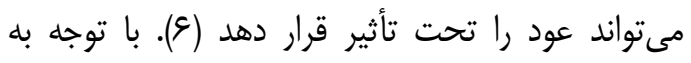
ماهيت مزمن و عودكنندة بيمارى اعتياد، عده فراوانى از

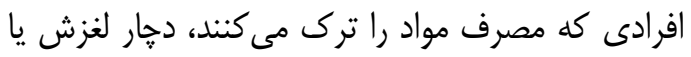
عود خواهند شد. ولع مصرف، نوعى ميل درونى (ذهنى)

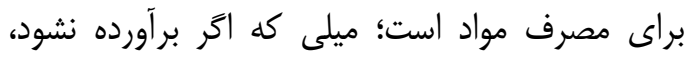

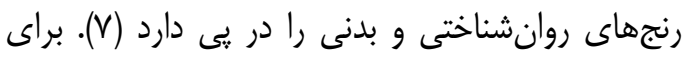

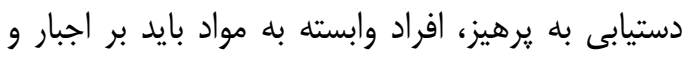

وسوسأ مداوم براى مصرف مواد غلبه كنند (^). در ميان خوشههاى اختلال شخصيت، خوشأ (ب) بالاترين ميزان همزمانى را با اختلالات سوءمصرف مواد إخصاد

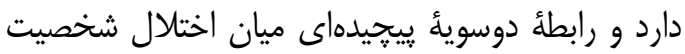
مرزى و مصرف داروهاى غيرقانونى وجود دارد (9). اختلال شخصيت مرزى، يك اختالال شخصيتى شديد ورهاي است كه با بزرگسالى زودرس ايجاد مىشود كه باليا اختلال در تنظيم هيجان، اعمال تحريكآميز، روابط

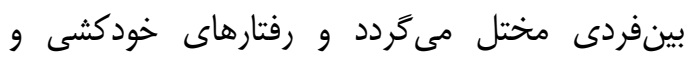

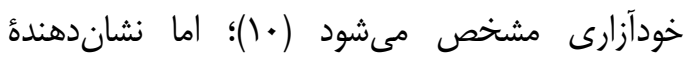
سطحى از سازماندهى / اختلال عملكرد شخصيتى است
مصرف مواد يكى از جدىترين معضلات بشرى در

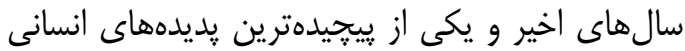

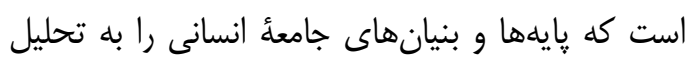

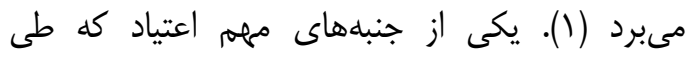
تلاشهاى بازدارنده مشخصشده، بازگشت به مصرف مواد مخدر يس از دورماى از قطع مصرف است. ترك بـ

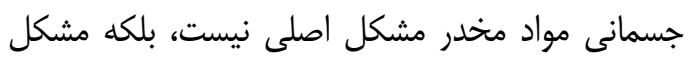

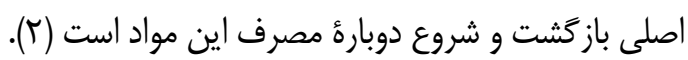
فقدان بررسى تفاوتهاى جنسيتى دربارة اعتياد و مسائل

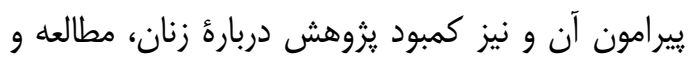

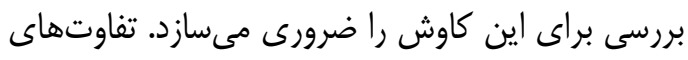
جنسيتى در نقشهاى اجتماعى و فرهنى بنى، همانند مخاطرات روانى و فيزيكى ممكن است مردان و زنان

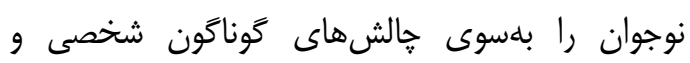
محيطى سوق دهد. جنين تفاوتهايى ممكن است در

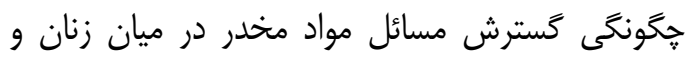
مردان نوجوان، جستجوى درمان و نحوهُ ياسخ دادن آنان مُنان

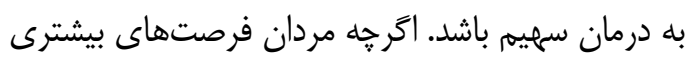
براى دستيابى به مواد و سوءمصرف آن دارند؛ اما قابليت

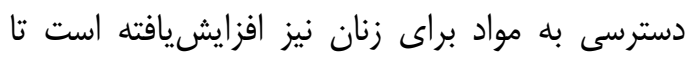

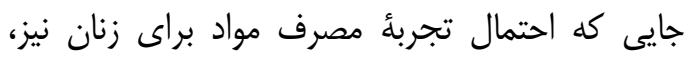
بلهسرعت در حال گسترش است. زنان معتاد در مقايسه با مردان، احتمال بيشترى دارد دهار ايدز و و ديكر

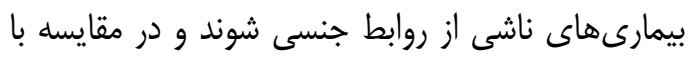

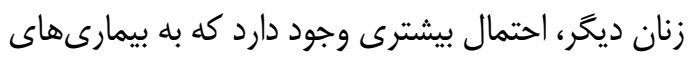

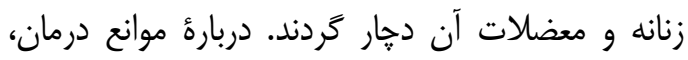

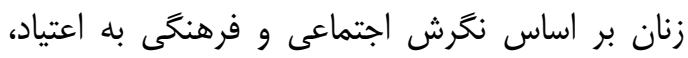

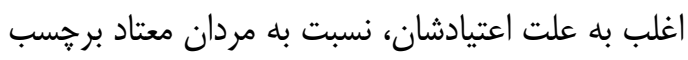

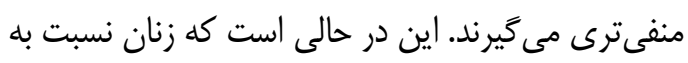

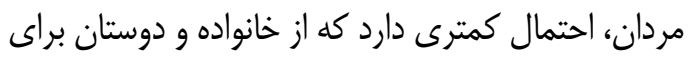
ترك مواد حمايت دريافت كنند (T). عود آثار نامطلوبى بر فرد و خانواده دارد. تأثيرات عود

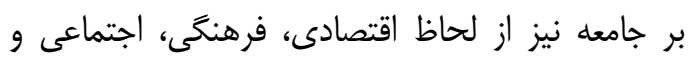

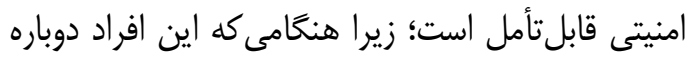
مواد مخدر مصرف مى كنند، از نظر روانى فشار شديدى

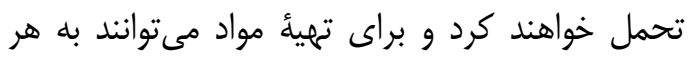
جرمى دست بزنند. با توجه به اينكه پِ إ از ترك و درمان موان 
مبتنى بر دلبستخى اهداف عمدهاى دارد كه شامل قطع

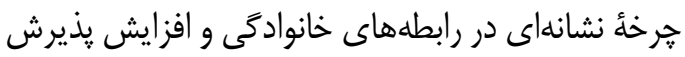

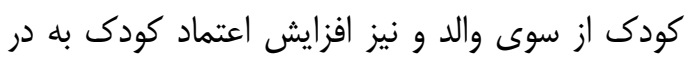
دسترس بودن والدين است. اين اهداف عمده امكان

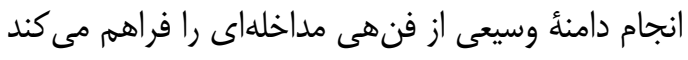

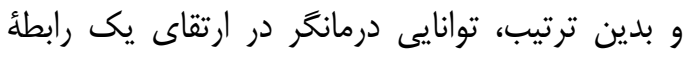

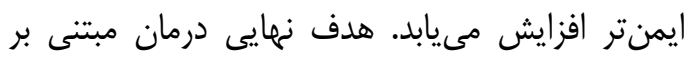

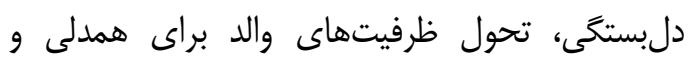

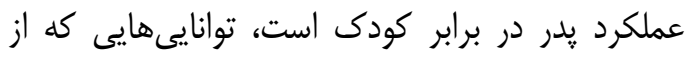

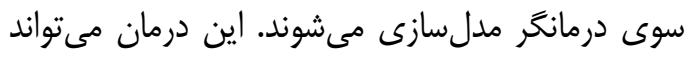

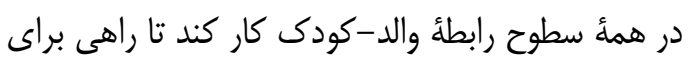

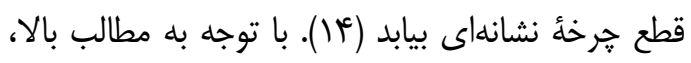

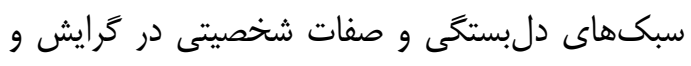
تداوم مصرف مواد مخدر، نقش تعيين كنندهاى دارند؛

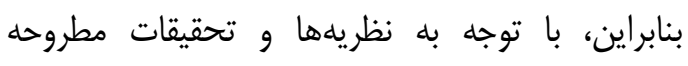

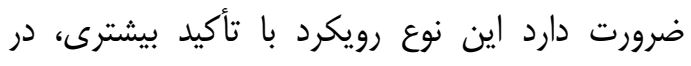

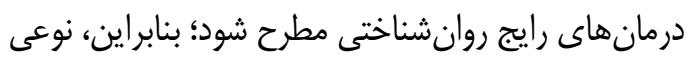
خلأ درمانى در اين زمينه وجود دارد و قصد محقق بر اين راني

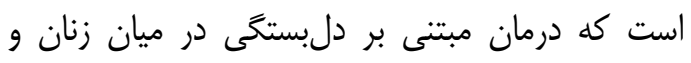

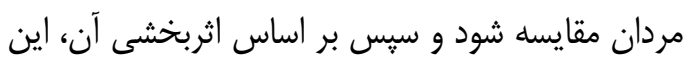

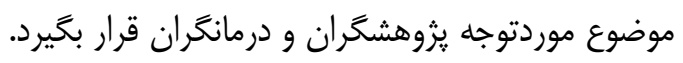

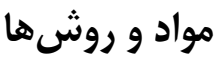

تحقيق حاضـــر نوعى تحقيق كاربردى (مداخلهاى)

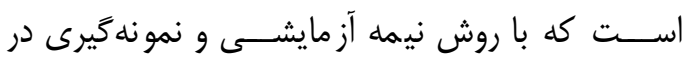

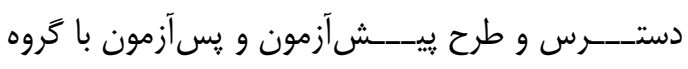
كواه و ييخيرى سلماهه انج-----مام شد (جدول شمارة
كه در دستهبندىهاى تشخيصى قرار مى گيرد. افراد

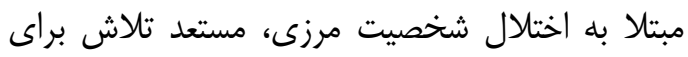

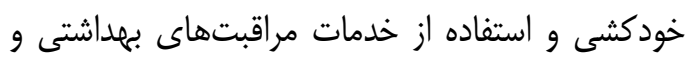
كزارش سطح جشمخيرى از اختلال در عملكرد شخصى، نقش و عملكرد اجتماعى هستند (1)

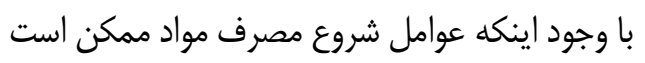

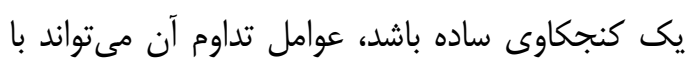
سبك دلبستخى مرتبط باشد. بر اساس خودتعيين گرىى،

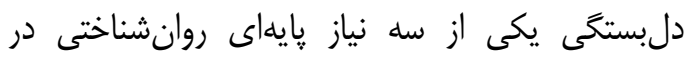

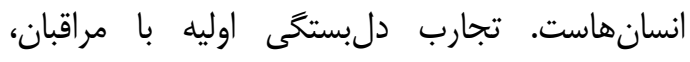
احساسات، افكار و رفتار را در روابط بعدى هدايت مى كند.

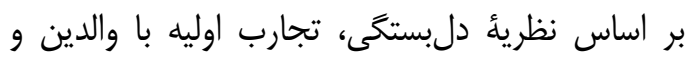

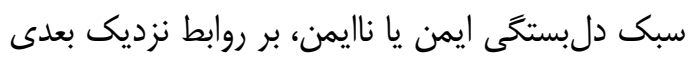

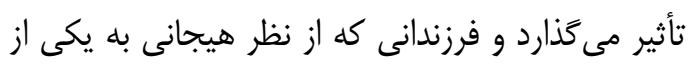

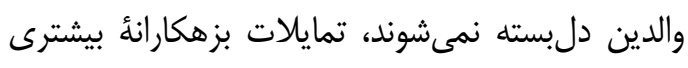

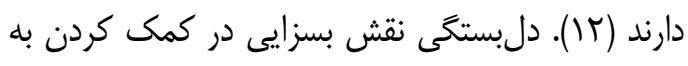

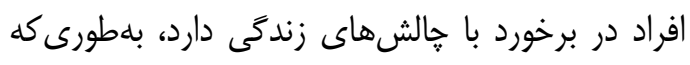
الكَوهاى دلبستخى ناسالم در دوره كودكى، مشكل رفتارى و اعمال بزهكارانه را در نوجوانى ايجاد مى كند. يافتهها نشان دادهاند كه مصرف مواد در ميان اعضاى خانوادههايى بيشتر است كه روابط صميمى والدين - نافنان فرزندان نداشته و بييوندهاى ايمن را تجربه نوانئ نكردهاند

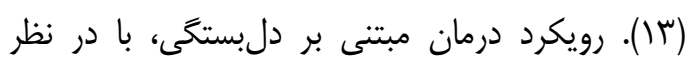

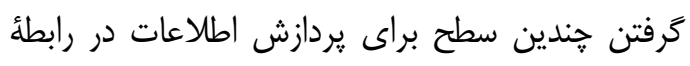

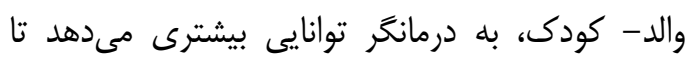

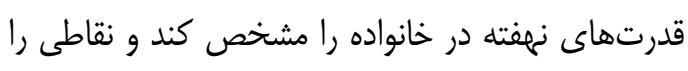

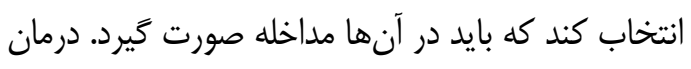

\begin{tabular}{|c|c|c|c|c|}
\hline \multicolumn{5}{|c|}{ جدول شماره ا. جدول الكوى روش يزوهش } \\
\hline بيشآزمون & أموزش & يس آزمون & بيخيرى بِ از سه ماه & \\
\hline $\mathrm{T} 1$ & $\mathrm{X} 1$ & $\mathrm{~T} 2$ & T3 & كروه آزمايش 1 \\
\hline $\mathrm{T} 1$ & - & $\mathrm{T} 2$ & - & كروه كَواه \\
\hline
\end{tabular}

در اب تداى يزوهش، از هر دو تروه (آز مايش و كَواه)

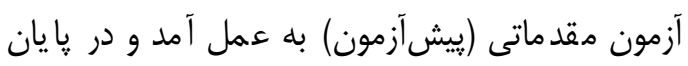

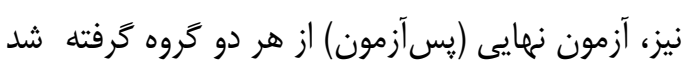

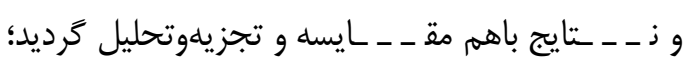

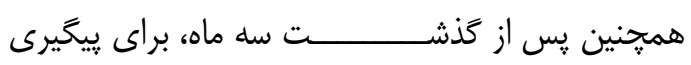

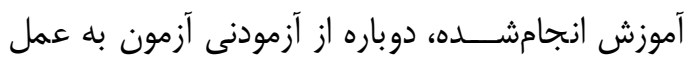

در اين طرح يزوهشـى، ما شـاهد حضــور دو كروه

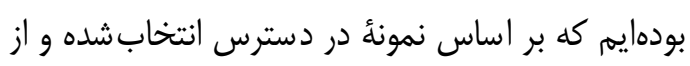

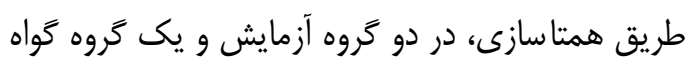

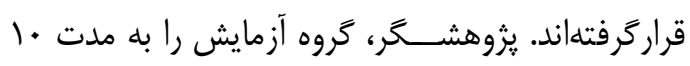

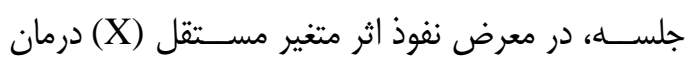

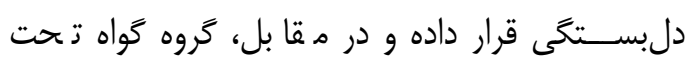

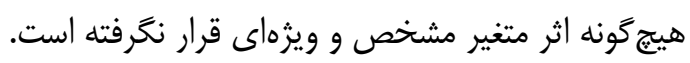


زيرمقياس تكانش گرى و و هيجانزدمى، ناميدى و و

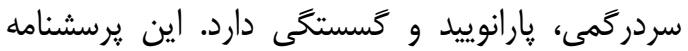
داراى اعتبار و روايى ايرانى است. بارئ

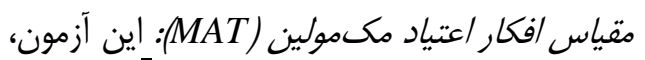

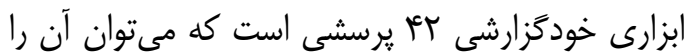
هم براى ارزيابى وضعيت مراجع و هم براى ارزيابى ميزان ييشرفت برنامهٔ درمانى بهكار برد. اين مقياس ينج

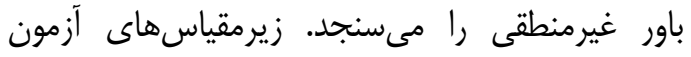

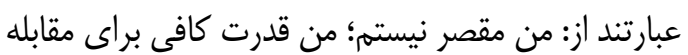

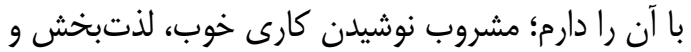
جالب است؛ من الكلى (معتاد به الكل) نيستم/ مشكلى إنى

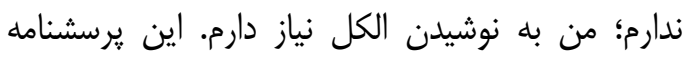
اعتبار و روايى ايرانى دارد. برسشنامئ محقق ساختئ عود، ولع، لغنش و بردين: اين يرسشنامه، شامل سٓ يرسش بر اساس مقياس

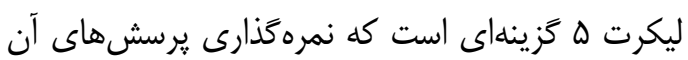
از خيلى كم= ا تا خيلى زياد =ه ه بوده است. بروتكل درمانى دلبستخى: برنامهُ مداخلهاى شامل

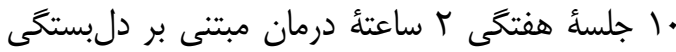
است (جهانبخش و همكاران، •وس ا1)
جامعأ آمارى تحقيق را هملُ افر اد واب سته به مواد با

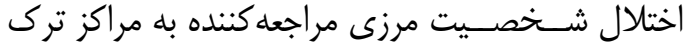

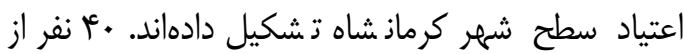

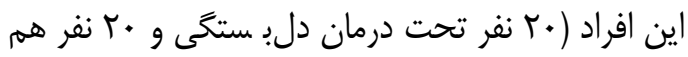
كروه كَواه) بهعنوان نمونه مشخص گَرديد كه اين تعداد، با استفاده از روش نمونه يَرى در دسترس انتخاب شد. در اين يزوهش از ابزارهاى زير استفاده گرديد:

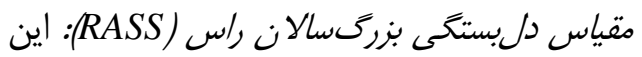

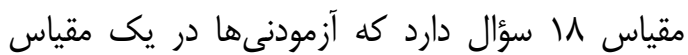
ليكرت ه درجهاى، ميزان موافقت يا مخالفت خود با هريك از عبارات را بيان مى كنند. اين يرسشنامه سه

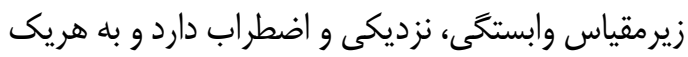
از اين زيرمقياسها ع عبارت اختصاص يافته است. براى

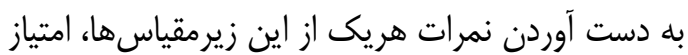
عبارات مربوط به آن، باهم جمع و بر تعداد عبارات (ع) بردات

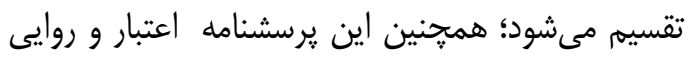

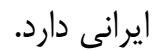
برسشنامة اختلال شخصيت مززى: اين مقياس باس گويه دارد كه ياسخ به يرسشها، بلهصورت دوززينهاى بله/ خير (بله=ا و خير=صفر) است. اين برسشنامه سه به به دورئه

\section{جدول شماره ؟. طرح درمان مبتنى بر دلبستكى}

\begin{tabular}{|c|c|}
\hline & جلسه \\
\hline 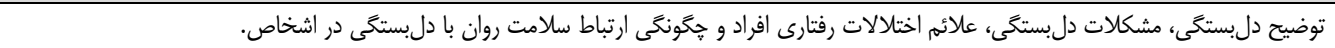 & اول \\
\hline 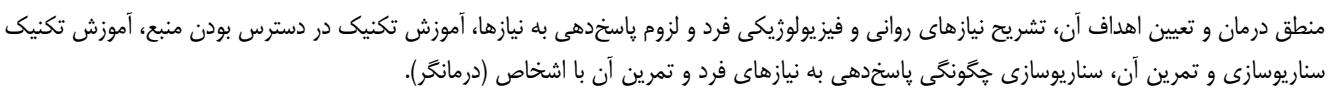 & دوم \\
\hline تكنيك ارتباط كلامى با افراد، تكنيك قصهَّويى، سناريوسازى دربارة يرسش و وِاسخ و ارتباط كلامى منبع و فرد و تفهيم جايكاه فرد در خانواده و ايجاد & سوم \\
\hline 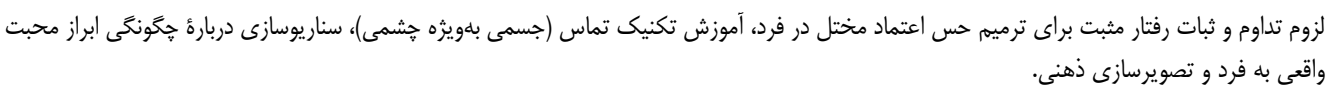 & جִهارم \\
\hline فرده، شوخى روابط دوستى فرد بان همَّنان و تشويق او به ايجاد ارتباط، فراهم كردن زمينُٔ مشاركت فعال فرد در وظايف كروهى، سناريوسازى درباره همراهى فعال & و ينجمم \\
\hline همكارى فعال در امور، سناريوسازى دربارة خكونكى همكارى و تعامل منبع با فرد در امور مربوط به او بهمنظور افزايش تعامل مثبت منبع با فرد و يرهيز از & ششم \\
\hline 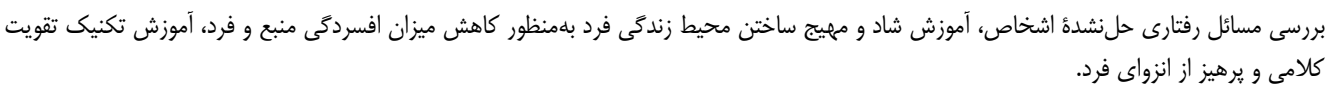 & 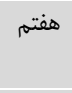 \\
\hline 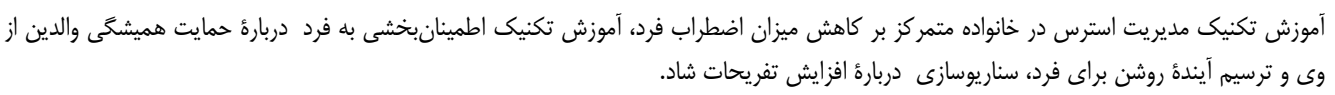 & هشتم \\
\hline 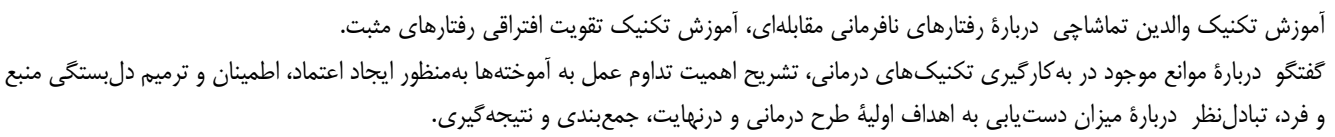 & نקهor \\
\hline
\end{tabular}


بر اساس اطلاعات جدول شماره (ب)، نمرات يس آزمون افرادى كه تحت درمان مبتنى بر دلبستخى قراركر فتلهاند، در

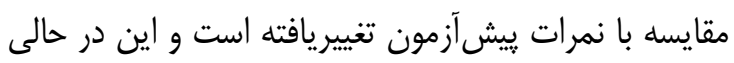

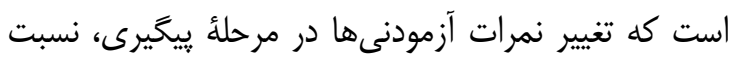
به يسآزمون تغيير فراوانى نداشته است.

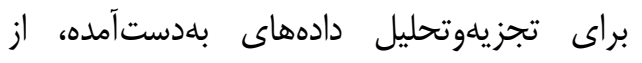
نرمافزار SPSS vol.23 و آزمون تحليل كوواريانس جندمتغيره، براى بررسى اختاف ميانخين ميان گَروهها استفادهشده است.

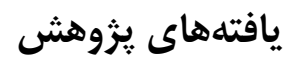

\begin{tabular}{|c|c|c|c|c|c|c|c|}
\hline يرهيز & ولع & لغزش & عود & & & & \\
\hline $19 / \pi \Delta$ & $11 / 94$ & $\mid V / 9 \Lambda$ & TN/TD & ميانكين & \multirow[t]{2}{*}{ ييشآزمون } & \multirow[t]{6}{*}{ مرد } & درمان \\
\hline $1 / 91$ & $1 / 4 \cdot 1$ & $1 / V^{e}$ & $1 / M \Lambda \mu$ & انحراف معيار & & & مبتنى بر \\
\hline rg/GA & $s / 11$ & $11 / .9$ & $r r / r v$ & ميانكَين & \multirow[t]{2}{*}{ پِ آزمون } & & \multirow[t]{10}{*}{ دلبستَى } \\
\hline $1 / r \cdot r$ & $r / \cdot V$ & $r / \cdot \Lambda$ & I/AT & انحراف معيار & & & \\
\hline$r \Delta / T$ & $\mathrm{~V} / \mathrm{M}$ & $11 / r \Delta$ & $r I / A V$ & ميانگين & \multirow[t]{2}{*}{ ييخيرى } & & \\
\hline $1 / 9 r$ & $1 / \Lambda 9$ & T/r & $r / M$ & انحراف معيار & & & \\
\hline r./VQ & $1 . / V \Delta$ & $W / \Delta$ & $r \cdot / \Delta$ & ميانكين & \multirow[t]{2}{*}{ ييشآزمون } & \multirow[t]{6}{*}{ زن } & \\
\hline $1 / V$ & $1 / V$ & $1 / r q$ & $1 / 79$ & انحراف معيار & & & \\
\hline$r V / V$ & $\Delta / \Delta$ & 11 & $r \varphi / \Delta$ & ميانكَين & \multirow[t]{2}{*}{ پِ آزمون } & & \\
\hline $1 / \Delta$ & $1 / r q$ & $r / / 9$ & $1 / N$ & انحراف معيار & & & \\
\hline re & 8 & $9 / \Delta$ & re & ميانكَين & \multirow[t]{2}{*}{ ييخيرى } & & \\
\hline $1 / 10$ & $T / A F$ & $1 / N r$ & $r / / 9$ & انحراف معيار & & & \\
\hline
\end{tabular}

است. در رابطه با لغزش، ولع و يرهيز از مصرف سطح

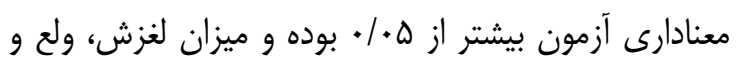

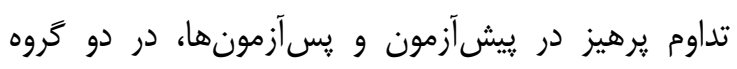
آزمايش و كواه تغيير داشته است؛ اما اين اختلاف ميان زنان

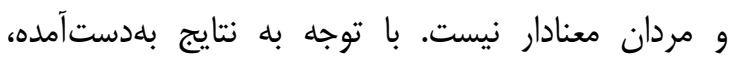
ماندكارى اثربخشى درمان نيز تأييدشده است.
يافتههاى بلهدستآمده از آزمون مقايسُٔ ميانخينها در

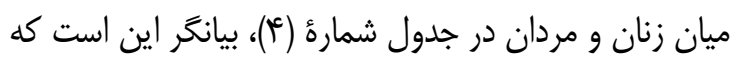

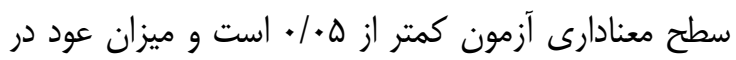

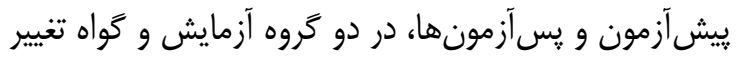

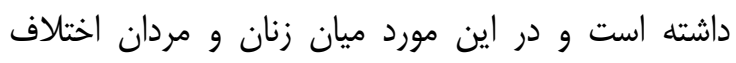
معنادارى وجود دارد و درمان مبتنى بر دلبستكى اثر كذار بوده است كه اين اختلاف در مرحلة ماندكارى نيز معنادار 


\begin{tabular}{|c|c|c|c|c|c|c|c|}
\hline سطح معنادارى & رسىشده & ميانكين مربعات & درجئ آزادى مئَ ميأ & مجموع ميانكين مربعات برواريانس & ت تايج آزمو & جدول شماره P & \\
\hline $.1 . .1$ & $11 . / 9 \cdot 4$ & $r q \cdot / 1$ & 1 & $r \varepsilon . / 1$ & آزمون & \multirow{3}{*}{ يِيشآزمون- پِسآزمون } & \multirow[t]{6}{*}{ عود } \\
\hline$\cdot+\cdots 1$ & $\mathrm{~V} / \mathrm{W} \mathrm{W}$ & IN/RTD & 1 & WNTRD & جنسيت & & \\
\hline & & T/MFA & rv & $\wedge \varepsilon / V \vee \Delta$ & خطا & & \\
\hline .1 .48 & $F / T A$ & $18 / 9$ & 1 & $18 / 9$ & آزمون & \multirow[t]{3}{*}{ ״س آزمون- ييخيرى } & \\
\hline .1 .48 & $F / T \Lambda$ & $19 / 9$ & 1 & $19 / 9$ & جنسيت & & \\
\hline & & $r / q \times q$ & rv & $\mid \notin 9 / 1$ & خطا & & \\
\hline $.1 . .1$ & r & EST/F & 1 & EST/F & آزمون ل & \multirow[t]{3}{*}{ يِيشآزمون- بِسآزمون } & \multirow[t]{6}{*}{ ل لغزش } \\
\hline.$|g| V$ & $\cdot / \Gamma \Delta \Delta$ &.$/ 9$ & 1 &.$/ 9$ & جنسيت & & \\
\hline & & $r / \Delta \Gamma$ & rv & $1 r \cdot / V$ & خطا & & \\
\hline - /ATA & $.1 \cdot 0$ & - /TTA & 1 & - /TTA & آزمون & \multirow[t]{3}{*}{ يسآزمون- يِيخيرى } & \\
\hline$\cdot / T M$ & $1 / 191$ & $\Delta / T \Delta F$ & 1 & $\Delta / T \Delta S$ & جنسيت & & \\
\hline & & F/DTV & rv & $\mid q V / \& q F$ & خطا & & \\
\hline $.1 . .1$ & $99 / 9.9$ & $r q 1 / 9$ & 1 & ५११/द & آزمون & \multirow[t]{3}{*}{ ييش آزمون - يس آزمون } & \multirow[t]{6}{*}{ ولع } \\
\hline$\cdot / T \Delta \Delta$ & 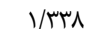 & $r / 9.9$ & 1 & $r / 9.9$ & جنسيت & & \\
\hline & & $r / q 19$ & rv & $1 . \vee / 994$ & خطا & & \\
\hline . /NQT & $r / I T r$ & $N$ & 1 & N/I & آزمون & \multirow[t]{3}{*}{ پِ آزمون- يِيخيرى } & \\
\hline וזוא. & I/FAF & D/GTA & 1 & D/GTD & جنسيت & & \\
\hline & & $r / v q 1$ & rv & $I F \cdot / T V D$ & خطا & & \\
\hline $.1 . .1$ & $199 /$ rq & $\Delta F \cdot / T T \Delta$ & 1 & $\Delta F \cdot / T T \Delta$ & آزمون & \multirow[t]{3}{*}{ بيش آزمون- پِسآزمون } & \multirow{6}{*}{ مصرف } \\
\hline$\cdot / \cdot \Delta S$ & r/A ^ & $1 \cdot 10 \cdot 9$ & 1 & $1 \cdot 10 \cdot 9$ & جنسيت & & \\
\hline & & $r / V \cdot q$ & rv & 1 ...RFe & خطا & & \\
\hline $.1 . .1$ & $I V / V \cdot D$ & r. & 1 & t. & آزمون & \multirow[t]{3}{*}{ پِ آزمون - ييخيرى } & \\
\hline \multirow[t]{2}{*}{.$/ 9 \Delta \Lambda$} &.$\cdot \cdot r$ & $.1 . .9$ & 1 & .1 .99 & جنسيت & & \\
\hline & & $r / T \Delta q$ & rV & $\Lambda \Psi / \Delta q)^{\circ}$ & خطا & & \\
\hline
\end{tabular}

مىرسد در زمينأ گرايش به سوءمصرف مواد مخدر زنان، هم

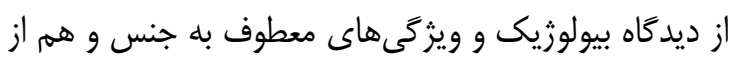
نظر ويزگى هاى فرهنگى و اجتماعى معطوف به جنس جنسيت

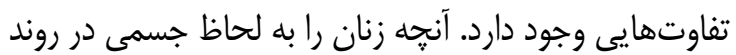
وابستخى، مشكلات جسمى و فيزيكى و روند درمان

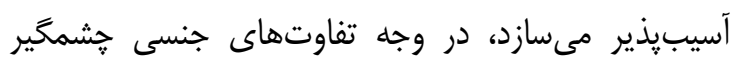

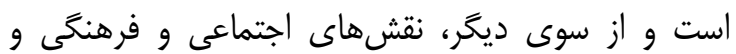

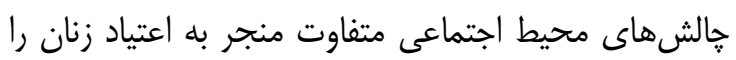
مىتوان در كليشهاى جنسيتى جامعأهُ هدف و تعاريف از

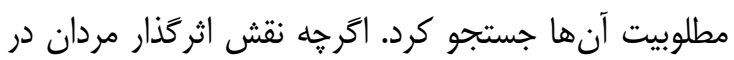

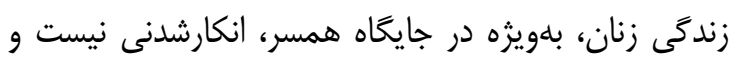

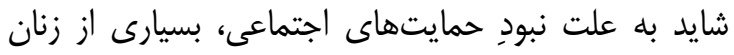

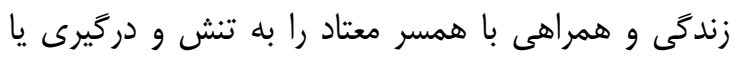

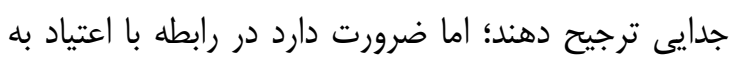

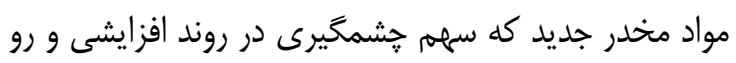
به رشد اعتياد زنانه دارد، با احتياط بيشترى نسبت بهانه هنين

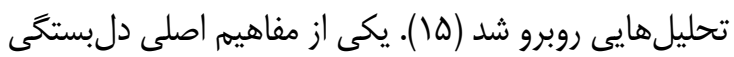

\section{بحث و نتيجلكيرى}

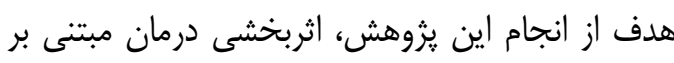

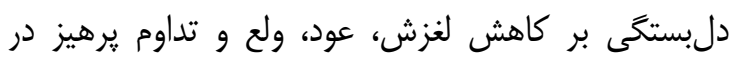

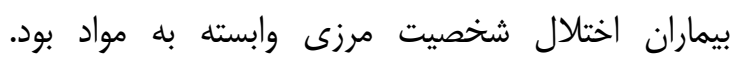

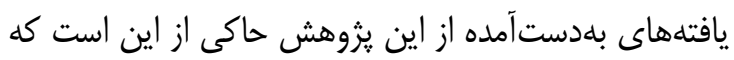

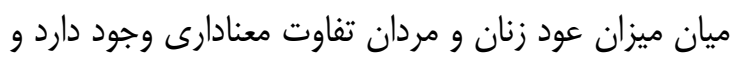

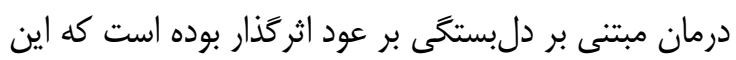

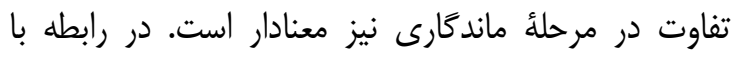
لغزش، ولع و يرهيز از مصرف سطح معنادارى آزمون بيشتر

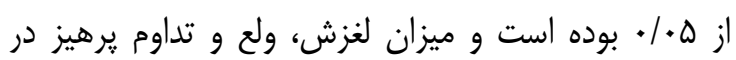

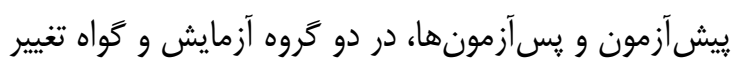
داشته است؛ اما اين تفاوت ميان زنان و مردان معنادار نيست.

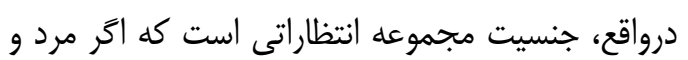

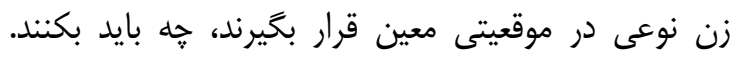
اصطلاح جنس بر تفاوتهاى بيولوزيك ميان زن و ور مرد

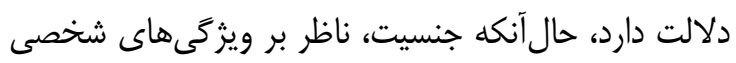

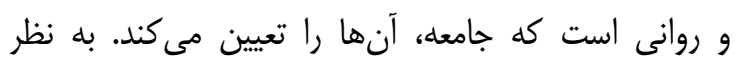


منابع اجتماعى در دسترس نباشند يا فرد مهارت به دست

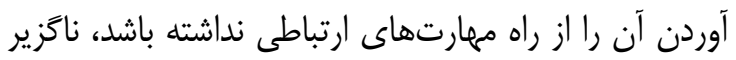
در اين شرايط، براى فرار يا تسكين خود به مصرف مواد

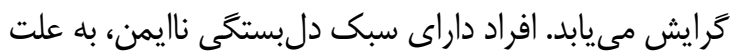

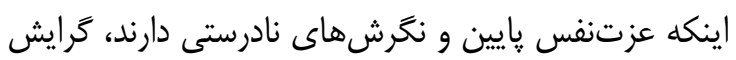

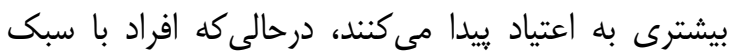
دلبستخى اجتنابى ممكن است تا حدودى، عزتنفس بيشترى نسبت به افراد با سبك دلبستخى ناليمن داشته باشد و عزتنفس مىتواند متغير تعديل كننده در گرايش آمادگى بـى

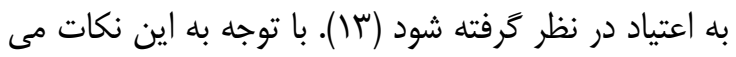

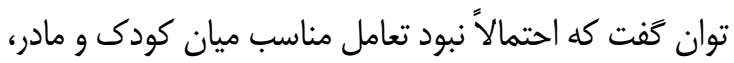

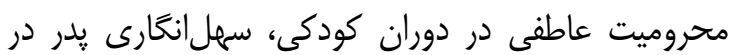
ارتباط با احتياجات عاطفى فرزند در دوران بلوغ، نبود تكيه

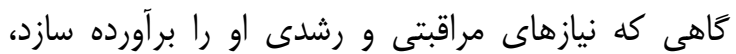

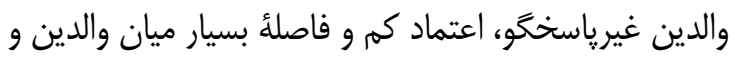
فرزند، نبود همدردى مشترى در مسائل استرسزا، ناتوانى والدين در بيان معقول احساسات خويش، انتقادات بىشمار و انتظارات بىاندازه خارج از توان جوان، دستبهدست هم مىدهند و جوان را به سوى مواد مخدر مى كشانند؛ بنابراين، درمان مبتنى بر دلبستخى با به كار گرفتن تكنيكهايى

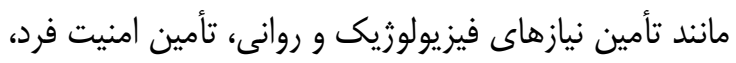

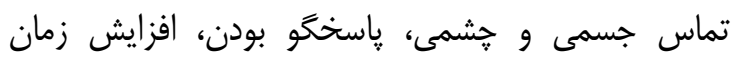

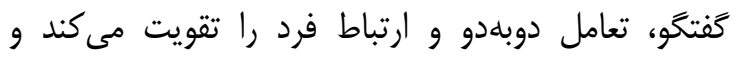

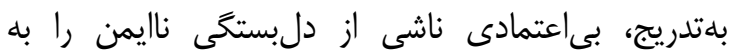

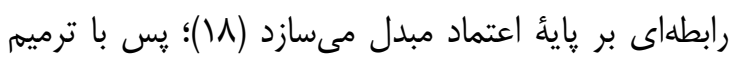
دلبستخى نايـــــــن و تقويت تعامل دوبهدو و ارتباط فرد و

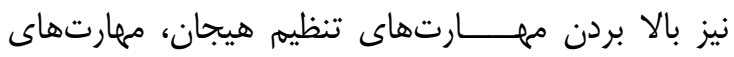
حل مسئله موجــــبات يــــــــيز از مصرف مواد را فراهم

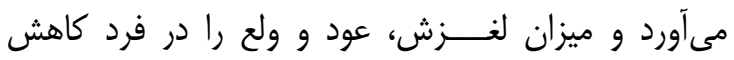
مى دهد.

كد اخلاق: IR.MEDILAM.REC.1399.280

\section{References}

1.Abolghasemi A, Kiamarsi A, Momeni S. [Temperament and character dimensions in narcotics addicts and normal people]. J Res Add Peres Drug Cont Head 2015; 27:12536. (Persian)

2.Shaterian M, Menati R, Kassani A, Menati $\mathrm{W}$. [Associated factors with addiction relapse in patients of referring to addiction treatment
اين است كه دلبستخى، الكوهاى فعال شناختى درونى

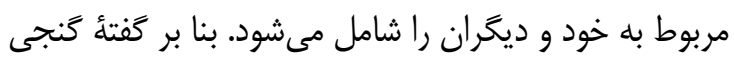
(IrVA)

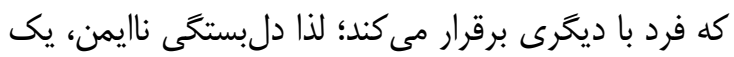
رابطه عاطفى منفى است؛ بنابراين، با شناسايى و تغيير افكار

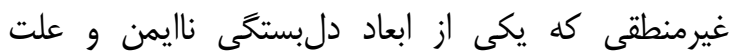

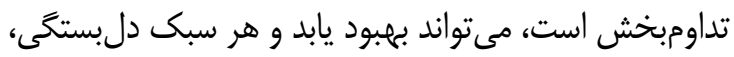

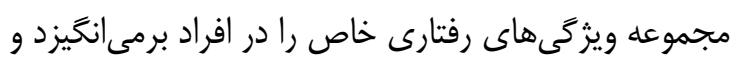

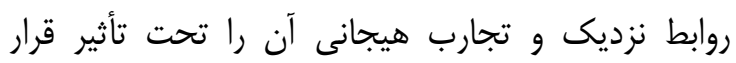

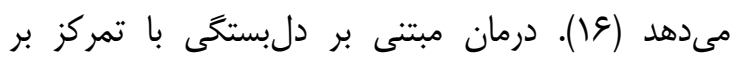

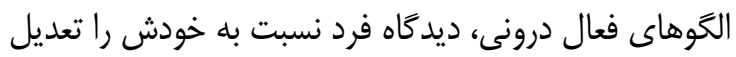

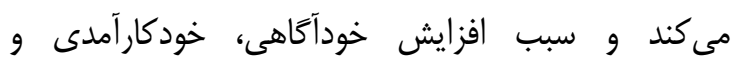

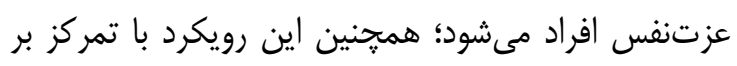

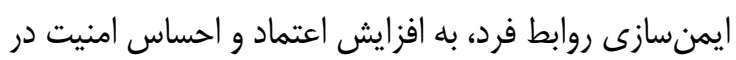

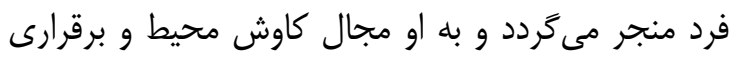

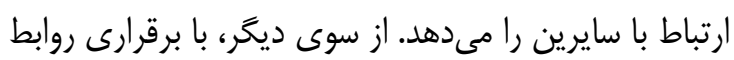

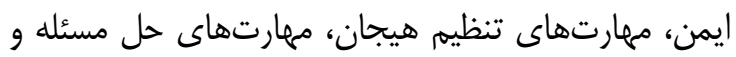

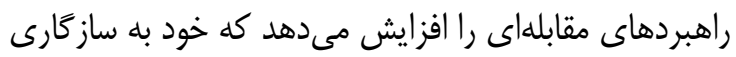

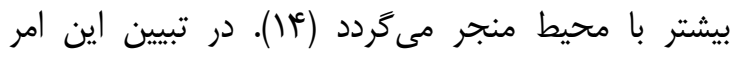

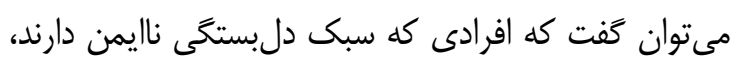

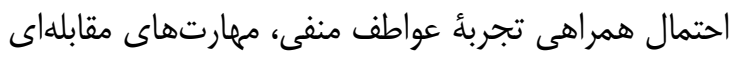

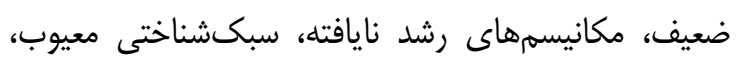
تعارض درونروانى و بينشخصى بيشترى دارند كه اين ماني

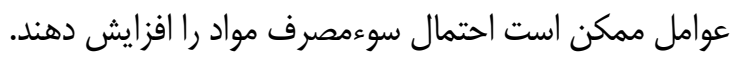

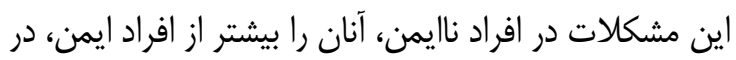

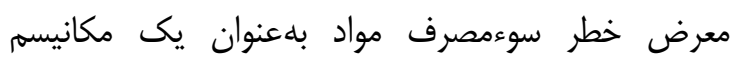
خوددرمانى، براى تعديل عواطف و تجارب منفى قرار مى سدهد موند

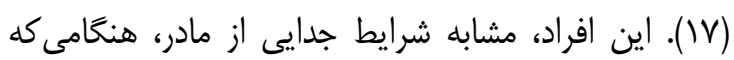

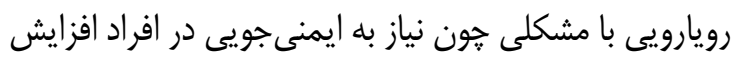

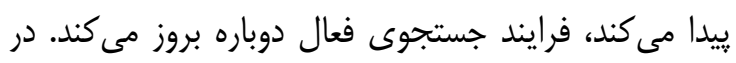

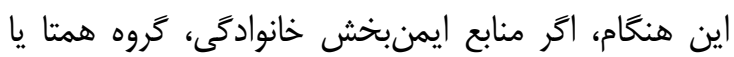

centers in Ilam a case controlstudy]. J Ilam Uni Med Sci 2015; 22: 165-73. (Persian)

3.Golestani F. [The impact of group therapy based on change stages in prevention relapse among substance abusers in Kerman]. Rese Add 2009; 2: 83-104. (Persian)

4.Nastizayi N, Hezareh Moghadam M, Mollazehi A. [The study of factors for recurred 
addiction from the view of self-introduced addicts to the addiction abandonment centers of Zahedan]. J Urmia Nurs Midwife Facul 2010; 8: 169-74. (Persian)

5.Sadok S. Summary of psychiatry and behavioral sciences. 1 Ed th. Sunders Publication. 2008; P.232-6.

6.Tajeri B, Ahad, H, Jamhari F. [The effect of cognitive behavioral therapy on abstinence temptation recurrence and change in glass addicts' attitudes]. J Clini Psychol Stud 2012;7: 22-7. (Persian)

7.Waezi K, Fallahikhoshknab M. Spiritual confrontation of recovered addicts against the desire to re-use drugs. J Qual Res Health Sci2017; 6: 449-60.

8.Makri A, Ekhtiari H, Edalati H, Ganjgahi H. [The relationship between craving and diverse aspects of addiction severity among heroin injection addicts]. Iranian Psychiatr Clini Psychol J 2008; 14: 298-306. (Persian)

9.Mashhadi A, Soltani Shurbakhorloo E, Razmjooei R. [On the relationship between emotional intelligence and symptoms of borderline personality disorder]. J Fund Mental Heallth 2010; 12:390-9. (Persian)

10.American psychiatric association. Diagnostic and statistical manual of mental

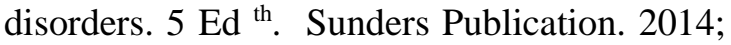
P.32-73.

11.Tomko RL, Trull TJ, Wood PK, Sher KJ. Characteristics of borderline personality disorder in a community sample comorbidity treatment utilization and general functioning. J
Personal Disord 2014; 28:734-50. doi.10.1521/pedi_2012_26_093

12.Ryan RM, Deci EL. A self-determination theory approach to psychotherapy the motivational basis for effective change. Canadian Psychol 2008; 49: 186-93. doi. 10.1037/a0012753

13.Haji Hassani M, Hashemi F. [Tendency to addiction The role of attachment styles]. Chaharmahal and Bakhtiari Disciplinary Encyclopedia 2017; No. 20: 25-38. (Persian) 14.Doran N, Mcchargue D, Cohen L. Impulsivity and the reinforcing value of cigarette smoking. Facul Publ Dep Psychol 2007; 283. doi.10.1016/j.addbeh.2006.03.023

15.Safari F. [Addiction and Women gender differences concerning drug abuse and its treatment]. Add Res Quarter 2003; 1: 119-39. (Persian)

16.Mousavi Z, Ghodsi A, Asadzadeh H. [The effectiveness of group counseling based on cognitive behavioral approach on changing students' attachment styles]. Evol Psychol Iranian Psychol 2012; 8: 262-78. (Persian)

17.Jazayeri A, Dehghani M. [Investigating the relationship between attachment styles addiction and psychological profile of addicted people in comparison with non-addicted people in self-reported centers of Bushehr province]. $\mathbf{J}$ Add Res2004; 2: 55-66. (Persian)

18.Guttman S, Crowell J. Attachment and externalizing disorders a developmental psychopathology perspective. J Am Acad Child Adole Psychiatr 2006; 45: 440-51. doi. 10.1097/01.chi.0000196422.42599.63 


\title{
Effectiveness of Attachment-Based Therapy in Reducing Slippage, Recurrence, Cravings, and Continued Abstinence in Drug-Dependent Borderline Personality Disorder Patients
}

\author{
Tahmasbian $H^{l}$, Ahmadi $V^{l^{*}}$, Mami $S^{l}$
}

(Received: June 29, 2020

\begin{abstract}
Introduction: This study aimed to investigate the effectiveness of attachment-based therapy in reducing slippage, recurrence, cravings, and continued abstinence in drug-dependent borderline personality disorder patients.
\end{abstract}

Materials \& Methods: This interventional semi-experimental study was conducted based on a pretest-posttest design with a control group and quarterly follow-up. The statistical population of the study was all people with substance abuse and borderline personality disorders who were referred to addiction treatment centers in Kermanshah, Iran. In total, 40 individuals were selected using the available sampling method, and they were then divided into attachment therapy $(\mathrm{n}=20)$ and control groups $(n=20)$. The data were collected using the Revised Adult Attachment Scale, Borderline Personality Disorder Questionnaire, McMullin Addiction Thought Scale, and a researcher-made questionnaire measuring slippage, recurrence, cravings, and abstinence based on attachment by Jahanbakhsh et al., 2011. Data analysis was performed in SPSS software (version 23) using multivariate
Accepted: October 13, 2020)

analysis of covariance to investigate the gender and mean differences between the groups.

Ethics code: IR.MEDILAM.REC.1399.280

Findings: The findings showed changes in the rate of slippage, recurrence, craving, and abstinence at pretest and posttest in both experimental and control groups. Moreover, there was a significant difference between males and females regarding the recurrence rate, which was also significant in the persistence stage. However, no significant difference was observed between males and females regarding slippage, craving, and continued abstinence.

Discussions \& Conclusions: Attachment-based therapy had effects on reducing slippage, recurrence, and craving, as well as increasing continued abstinence.

Keywords: Attachment therapy, Borderline personality disorder, Drug-dependent males and females, Slippage, Recurrence, Craving, Continued abstinence

1. Dept of General Psychology, Ilam Branch, Islamic Azad University, Ilam, Iran

*Corresponding author Email: Vahid_ahmadi20@yahoo.com 